\title{
Research on satisfaction of Public Cultural Service in Kunming
}

\author{
Wang Qiu $^{1}$,Gan Kaipeng ${ }^{2}$ \\ School of Finance and Public Management, \\ Yunnan University of Finance and Economics,Kunming, China \\ 1.397169925@qq.com; 2.937618678@qq.com
}

\begin{abstract}
Based on empirical investigation of 69 villages of 32 towns in Kunming city, the article analyses the satisfaction and its influencing factors of rural public cultural service. The results show that the satisfaction of public cultural service is relative high in the rural area, but most rural residents have a little awareness and participation about public cultural service. The Education and occupation of rural residents as well as awareness and participation have significant impact on the satisfaction of public cultural service. The article puts forward some suggestions for the development of rural public cultural service, such as further increase the supply of rural public cultural services, promoting policy publicity and implementing effective assessment mechanism.
\end{abstract}

Keywords: Rural Residents; Public Cultural Service; Satisfaction

\section{INTRODUCTION}

Since the reform and opening up, with the continuous development of the socialist market economy, our society has changed from the general pattern of food and clothing to the type of all-round development. The cultural needs of the people are increasing day by day, and the way of consumption has undergone profound changes. This has injected new vitality into the cultural development, and inevitably put forward new requirements for the provision of public cultural services. The construction of public cultural service system is a long-term strategic task for the development of our country's economy and society and the construction of service-oriented government.To improve the level of public cultural services and enhance the public satisfaction with public cultural services is an important responsibility of government departments in China, but also a basic prerequisite for the construction and development of service-oriented government

The sixth meeting of the 17th Congress of the communist Party of China adopted the "decision of the CPC Central Committee on deepening the Reform of the Cultural system which has promoted the great development and prosperity of socialist culture in October 18, 2011.

The decision put forward an important deployment to deepen the reform of the cultural system for the public cultural development. In terms of the deployment of the public cultural service system, the decision points out that "meeting the basic cultural needs of the people is the basic task of the construction of socialist culture". We must adhere to the government's leading role ad strengthen the construction of cultural infrastructure in accordance with the requirements of public welfare, equality, basic service, improve the public cultural service network, and enable the masses to enjoy free or preferential basic public cultural service. Assessed by "public experience" as the starting point, the survey product the site experience and the public satisfaction investigation aimed to promote the development of public cultural service in Kunming.

\section{SURVEY INDEX SYSTEM AND METHOD}

In this paper, the authors have investidgted 5 venues (Kunming Library, Kunming Museum, Kunming Cultural Museum, Yunnan Military Academy, and Kunming Nie-er Memorial), the Libraries culture museum in 12 counties and the culture station (room) of the town (street) in 17 districts of Kunming. Surrounding the managenment system, service attidutes, environmental construction, service content, professional quality, the satisfaction scale was designed adopting the the form of the rike's scale.

The questionair of public satisfaction inludes three dimensions: cognition, participation, satisfaction. The coginitive index mainly measrures the awareness and recognition of the public cutltural service institutions, such as location, opening time, public cutlrual service activities and free public cutlrual service and so on.

The participation indicator mainly measures the public participation of various cultural activities held by the public service institutions, including the participation rate of public cultural service activities and the ways of participation in public cultural activities. The satisfaction index mainly measures people's satisfaction with basic service provided by public cultural service institutions, including environment construction, service attitudes, and professional knowledge and so on. We have collected 1845 samples from the areas covered by Kunming cultural service institutions through random sample survey.

\section{RESEARCH DISCOVERIES}

\section{A. Descriptive analysis of sample}

The survey was conducted in 5 venues in Kunming, 12 counties under the jurisdiction of Kunming, and 5 
developments (holiday) coverage areas. Total 1884 effective questionnaires were collected with a recovery rate of $97.3 \%$. Among the 1884 effective questionnaires, total 1845 valid questionnaires were actually used. The sample of this survey consists of the following parts:

From the sample, males accounted for $42.4 \%$, and the average age of all samples was 27.16 years. In terms of education level, the educational level of the sample is generally low, mainly secondary school education, accounting for $47.2 \%$, accounting for $15.3 \%$ of college and undergraduate education, and $11.1 \%$ of postgraduate or higher education. In the profession, the proportion of farmers accounted for $17.6 \%$, the proportion of individual occupations accounted for $20 \%$, and the proportion of other occupations was $16.6 \%$. From the average monthly income, $96.6 \%$ of the people had a monthly income of less than 6000 yuan. The basic information of the sample is shown in table3-1.

Table 3-1 Descriptive analysis of the basic variables of the sample $(\mathrm{N}=1845)$

\begin{tabular}{|c|c|c|c|}
\hline Index & $\begin{array}{l}\text { Frequenc } \\
(\%)\end{array}$ & Index & Frequency $(\%)$ \\
\hline Gender & & Household registration & \\
\hline Male & 42.4 & Residence of the city & 82.8 \\
\hline Female & 52.8 & $\begin{array}{l}\text { Nonlocal registered permanent } \\
\text { residence }\end{array}$ & 15.2 \\
\hline Educational level & & Career type & \\
\hline Primary and below & 19.4 & State organs/institution cadre & 2.6 \\
\hline Junior middle school & 29.0 & $\begin{array}{l}\text { State organs/Staff of a public } \\
\text { institution }\end{array}$ & 4.9 \\
\hline Senior middle school & 18.2 & Enterprise Manager / Manager & 2.7 \\
\hline Junior colldge & 6.2 & Technical staff of enterprises/staff & 3.8 \\
\hline Undergraduate & 9.1 & Enterprise/service staff & 7.7 \\
\hline Postgraduate and above & 11.1 & Scientific and technical personnel & 1.8 \\
\hline Monthly income & & Retired personnel & 11.4 \\
\hline Less than 1500 yuan & 23.6 & Enterprise and mine maunual workers & 4.9 \\
\hline $1500-3000$ yuan & 36.8 & Taxi driver/driver & 1.6 \\
\hline $3000-4500$ yuan & 18.0 & Self-employed person & 20.0 \\
\hline $4500-7500$ yuan & 1.2 & farmer & 17.6 \\
\hline 7500 yuan and above & 1.6 & other & 16.6 \\
\hline
\end{tabular}

\section{B. Overall ranking of Public satisfaction}

According to the calculation formula of public cultural service satisfaction score, the public cultural service institutions are divided into three categories including Kunming Municipal Stadium, 5 Kunming City Development Zone (holiday) and 12 counties.

The satisfaction comprehensive score ranking from high to low is: Kunming library, Kunming Nie-er memorial hall, Yunnan military academy, Kunming museum. The average score of the total satisfaction of the 5 venues in Kunming is 71.3. According to the results, the satisfaction comprehensive score of Kunming development zone rank from high to low is: Kunming high tech-Zone, Kunming economic development zone, Kunming two-district Tangdian industrial park and
Jiaozishan Tourism development zone, Dianchi tourism resort, Kunming Yangzonghai scenic area. The average score of public satisfaction of public cultural service institutions in Kunming development zone is 68.8.

The results show that the total score of public satisfaction of the public cultural service institutions in 12 counties in Kunming ranked the top five: Wuhua district, Luquan County, Chengong district, Panglong district and Guandu district. The average score of public satisfaction of public cultural service institutions in 12 counties is 70.8 . 
Table 3-2 the ranking of public satisfaction in 12 counties (districts) in Kunming

\begin{tabular}{|c|c|c|c|}
\hline types & venue name & $\begin{array}{c}\text { satisfacation } \\
\text { score }\end{array}$ & $\begin{array}{c}\text { rank of } \\
\text { satisfacation }\end{array}$ \\
\hline \multirow{12}{*}{ counties/areas } & Wuhua area & 79.24 & 1 \\
\hline & Luquan county & 76.38 & 2 \\
\hline & Chenggong area & 75.28 & 3 \\
\hline & Panlong area & 74.29 & 4 \\
\hline & Guandu area & 73.26 & 5 \\
\hline & Fumin county & 72.57 & 6 \\
\hline & Dongchuan area & 69.04 & 7 \\
\hline & Xundian county & 69.02 & 8 \\
\hline & Jinning county & 68.26 & 9 \\
\hline & Xishan area & 66.96 & 10 \\
\hline & Shilin county & 63.07 & 11 \\
\hline & Yiliang county & 62 & 12 \\
\hline \multicolumn{2}{|c|}{ Mean of satisfacation } & \multicolumn{2}{|c|}{70.78} \\
\hline
\end{tabular}

\section{Awareness of public cultural services}

The survey of public cultural services according to different types of analysis service awareness, but considering the service awareness is a subjective awareness of public cultural services in Kunming City, and public cultural services area or administrative level there is no necessary correlation, so this research tends to be 22 different types the public cultural service awareness in the same standard of comparison, the Kunming municipal 5 venues, 5 Kunming City Development (resort) 12 County District, Kunming city (District) degree level of public cultural services of the publices Service awareness.

The comprehensive awareness of public cultural service institutions in Kunming is $67.23 \%$ and only 8 public cultural service institutions or regional public cultural service institutions have higher comprehensive awareness than average value with a percent of $36.36 \%$.So the public awareness of grass roots Public Cultural Services in Kunming is relatively low which affects the participation of the masses in all kinds of cultural services held by public cultural service institutions in a certain extent,

\section{Participation in public cultural services}

Considering the degree of service participation is a subjective behavior of cultural service activities organized by public cultural service institutions in Kunming, this survey tends to place 22 different types of public cultural service institutions on the same comparative standard. The average participation of public cultural service institutions in Kunming is $38.75 \%$ and only 9 public cultural service institutions or regional public cultural service institutions have higher participation than the average with a percent of $40.90 \%$. The public participation of grass roots Public Cultural Services in Kunming is relatively low which is influenced by the awareness of public cultural services in a certain extent, because many people even don't know where the public cultural service institutions are located.

\section{CONCLUSIONS}

Using the empirical investigation of 69 villages in 32 townships in Kunming city, the paper analyzes the influencing factors of rural residents' public cultural service satisfaction. The paper puts forward the following advices:

\section{A. Perfecting the basic public culture service budget system at the grass-roots level.}

According to the priority of social goals to the principles of economic objectives, the government should establish a growth mechanism and a tilt mechanism of public cultural input and construct the public service budget system at the grass-roots level. Based on the establishment of the total volume of public cultural budgets, it should be clearly stipulated that the growth rate of rural public cultural investment is faster than that of urban areas, so as to gradually increase the proportion of public cultural service investment to public cultural resources. In addition, in order to further supervise the effective implementation of the operation mechanism of grass roots public cultural services, the local government should link the public financial investment to the public cultural services in the grass-roots area and the department performance appraisal which can effectively improve the operation effect of public cultural services in basic areas.

\section{B. Improving the operation and management mechanism of public cultural service.}

With the development of economy and society, the spiritual and cultural needs of the grass-roots people are showing diversified and multi-level characteristics, so the content of grass roots Public Cultural Services also needs to be redefined with social needs. Firstly, the content of 
the service should be redefined including development goals, scope of services, service items and specific services, so as to adapt to the diverse cultural needs of the grass-roots areas. Secondly, the facilities construction standards should be adjusted according to new service needs. In the long run, cultural integration must be reflected in the construction of cultural facilities at the grass-roots level, especially establishing the comprehensive cultural station and corresponding facilities.

\section{Introducing the accountability and accountability mechanism.}

In a word, local governments must disclose to the public about the management system, major decisions, implementation effects and fiscal revenue and expenditure in public service, including budget plan, investment status, service standard and funds utilization. The effective performance appraisal system should include the following several aspects: (1) establishment of performance management contract system; (2) establishing the responsibility system for the operation of basic public culture service; (3) perfecting the audit supervision system.

\section{FUNDING}

This work is supported by the program of "Research on satisfaction of rural public cultural service in Yunnan border area (project number: 2018YUFEYC028)" from the graduate innovation fund project of Yunnan University of Finance and Economics.

\section{REFERENCES}

[1] Sun Jianjun. Research on the Policy of Equalization of supply of basic Public Services in China [M]. Beijing: Intellectual property publishing, 2012. (In Chinese)

[2] Peng Jing. Analysis of influencing factors on satisfaction degree of basic Public Service in migrant Workers'Inlet: a Survey based on Shenzhen P New area [J]. Journal of Xi'an Jiaotong University (Social Science Edition), 2016(6):68-74. (In Chinese)

[3] Lu Chunlong. A Survey of Peasants' satisfaction with Rural Public Cultural Service: findings from Nine provinces and cities in China [J]. Journal of China University of political Science and Law, 2014 (2):59-66. (In Chinese)

[4] Zhu Guowei \& Zheng Pei. Rearch on theory and practice of public satisfaction assessment from the perspective of service-oriented government [M]. Beijing: Science Press, 2010. (In Chinese)

[5] Liu Jinlan. Customer Satisfaction and ACSI[M]. Tianjin: Tianjin University Press,2006. (In Chinese)

[6] Ma Xiuling \& Zhang Bing. Study on citizen satisfaction degree of county government Public Service--comparative analysis based on questionnaire survey in three counties of Guangdong, Henan and Gansu [J]. Journal of Lanzhou University, 2016(1):149-159. (In Chinese)

[7] Kelly J. M. Windell D. A. Multiple-indicator approach to municipal service evaluation: correlating performance measurement and citizen satisfaction across Jurisdictions [J].Public Administration Review, 2002,62(5):610-621. (In Chinese)

[8] Zhou Quanhua \& Liu Yan. The evaluation Index system of public Cultural servicet satisfaction--based on the empirical analysis of
Shanghai X community [J]. Social Science, 2012(3):244-245. (In Chinese)

[9] Chen Ying. A survey on the demand and satisfaction of public cultural service in Shenzhen Guangming new zone [J]. Library Research and Work, 2013(4):2-6. (In Chinese)

[10] Zhou Changcheng \& Ye Mingshen. Research on satisfaction degree and decision mechanism of rural public cultural service in the view of demand [J]. Journal of Hubei Administration College, 2015(6): 41-45. (In Chinese)

[11] Feng Fei \& Zhong Yang. An analysis of the factors influencing public satisfaction of urban public service in China--a survey based on the public satisfaction of 10 cities [J]. Journal of Shanghai Administration College, 2016(2):58-75. (In Chinese)

[12] Jiang Xiaojie \& Zhao Chunsheng. Public satisfaction assessment of public service supply in county-level government--based on the empirical data of Kaiyuan large samples in Yunnan province [J]. Administrative Forum, 2013(1):46-51. (In Chinese) 